\title{
Architectural Features of Adjacent River Residence in Shaoxing
}

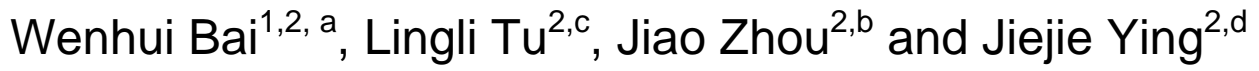 \\ ${ }^{1}$ Department of architecture, Shaoxing university, Shaoxing, Zhejiang, 31200, China \\ 2 Department of civil engineering, Shaoxing university, Shaoxing, Zhejiang, 31200, China \\ abaiwuhui2010@gmail.com, ' $1047642707 @ q q . c o m$, \\ b285293315@qq.com, d498674362@qq.com
}

\begin{abstract}
Keywords: Adjacent river residence, Architectural features, Formation, Architectural form, Private pier, Public pier.
\end{abstract}

\begin{abstract}
The adjacent river residence in Shaoxing is different from the Taimen residence (i.e., the grand courtyard in Shaoxing's residence), most of which are owned by the lower classes; therefore, there are almost no rules or regulations constraining them in construction. The seamless integration of water and constructions, and the artful layout of manual work and the nature are the watery region style of Shaoxing which is different from other cities. This paper analyzes the developed water transportation and thriving commercial trade of ancient Shaoxing, which is an important factor for the formation of the overall building layout of the adjacent river residence. The architectural Plan Layout of the adjacent river residence, with a high internal space utilization rate, is an economical and affordable residential form. Private pier and public pier are the distinctive architectural forms of the adjacent river residence, which plays an integral role in the life of the residents near the river. Exploring the architectural art of the adjacent river residence in Shaoxing is beneficial to inherit the essence of residence in Shaoxing, so that to achieve the goal of striving to combine the modern architectural features, technology with the traditional architectural culture, and to develop the excellent cultural heritage of residence in Shaoxing watery region.
\end{abstract}

\section{Introduction}

Shaoxing is a water city in Southern Yangtze regions, known as an "Oriental Venice"(i.e., a land that abounds in rivers and lakes). The weather there is subtropical monsoon climate, warm and humid with four distinct seasons. It is located in the south of Hangzhou Bay, the western part of the Ningbo-Shaoxing Plain, with a terrain from tilting from the southwest to northeast. The southwest of Shaoxing is hilly with Kuaji Mountains stretching among this area. The northeast is full of beautiful lakes and fertile fields, with more than $1900 \mathrm{~km}$ of rivers and streams flow through this area, and more than 3,000 bridges constructed on Jianhu River areas surrounding the city. Inside the city, the crystalline water flows along the green mountains, the round bridge openings connect the wending rivers, and Wupeng boat transport people and cargos from the house near the river. This scene is described as "boating along Shaoxing city river network is just like traveling in a mirror midstream".

There were originally nine gates in ancient Shaoxing city wall. Only two of them are land gates, and the rest are Watergates. Through six vertical and 12 horizontal river trunks and winding water ally, the clean water in Jianhu lake flows into the city, as shown in figure 1 . On both sides of river, the roofs of the civil residence connect with each other, the streets adjacent the river, bridges attach the road, and the neighborhoods live between the river and the road. People living in every house can step along to the lower river, which is what a saying goes "ten thousand Lanes spiral along three mountains, and hundred of bridges and streets run through the rivers”. The seamless integration of water and constructions, and the artful layout of manual work and the nature are the features of this place with Jishan Mountain and Jianhu Lake in it differ from other cities. 


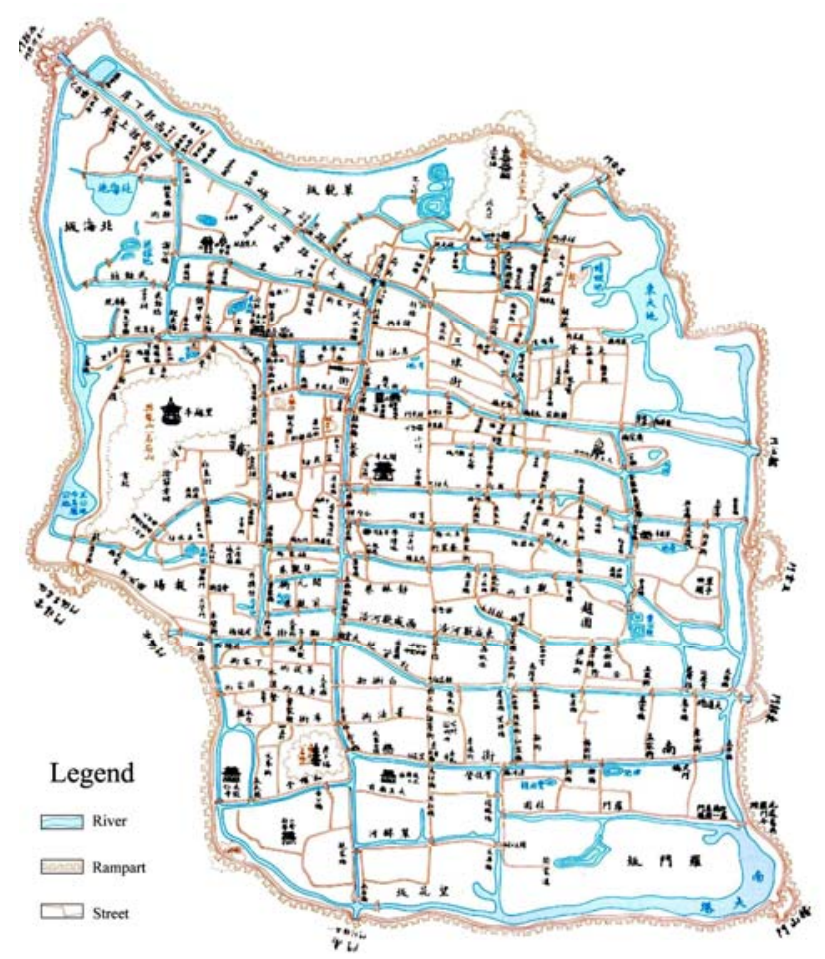

Fig. 1 Shaoxing city street graph of Qing Dynasty

\section{Adjacent river residence formation}

Forest-clad mountains and limpid streams complete the scene of ancient Shaoxing city. The Shaoxing residence have a long history, the the white wall, black tiles, brick, and column all filled with the fragrance of the ancient culture. There are two typical types of Shaoxing houses, this is, adjacent river residence and Taimen residence. The layout of Shaoxing Taimen residence firmly imprints the features of big family. In these grand courtyards, many people of the big family live together, and the houses are symmetrically arranged in vertical and horizontal plane, which is embodied the essence of the ethics in feudal system. However, adjacent river residence in Shaoxing mostly owned by the lower classes and there are almost no rules or regulations constraining them in construction.

Water is the soul of Shaoxing city, and it is the media of transportation and trade in this city. The the adjacent river residence in Shaoxing develops from this characteristic environment. As early as in Song Dynasty, Water transportation in Shaoxing was very developed. In Qing Dynasty, Shaoxing wine industry went into the heyday period. The owners of the workshop organized the fleet themselves to purchase glutinous rice for wine-making from the area of Jiangsu Wuxi and Danyang, and sold the Shaoxing rice wine throughout the country and even overseas, known as "the shaoxing wine travels around the world". The developed water transportation and thriving commercial trade of ancient Shaoxing play an important role in the formation of the overall architectural Plan layout of the adjacent river residence. Along the both sides of the river, people build their houses or set the streets, and construct the house along the street, and gradually formed the layout of "a river with no street", "a river and a street”, and "two streets mingle a river", these layouts are shown in Figure 2-5. The layout of the adjacent river residence mainly stretches horizontally, and is vertical to the river. There is no window in side walls s that they can be close to their households, while the internal ventilation and lighting rely on cleverly interspersed small patios which covers small areas. Generally, the side along the street is designed with a high window or wood block door to exclude the interference of sight and to ensure the quiet indoor. The area near the water is usually more open, so the walls retreating few steps will form a small open hall or small platform facing the water, or stretch a section of backrest railings lead by a private pier to the water to form a good place for enjoying the winter sun or summer wind and for general household operations. The first or the second floor of the house near the street 
are generally the living rooms or stores, the side near the rear are kitchen, toilet or warehouse, and the middle parts are used as bedroom or workshop and so on. The upstairs usually are bedrooms. This arrangement provides the residence with a high internal space utilization rate, and makes the adjacent river residence an economical and affordable residential form.

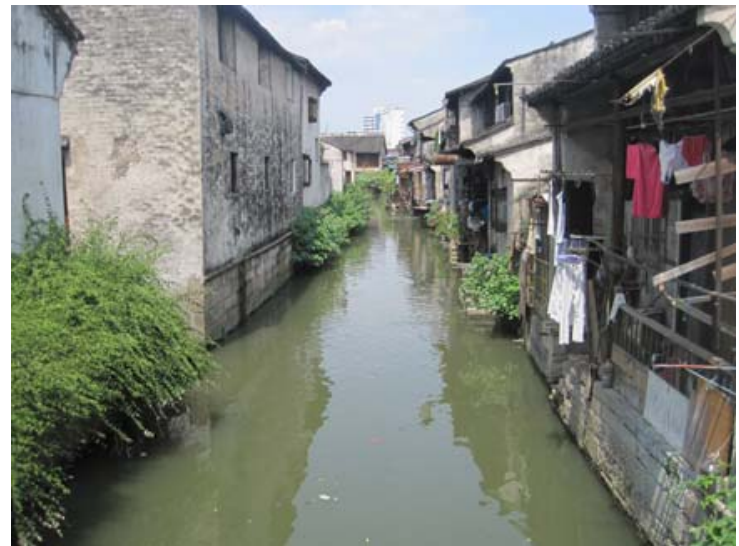

Fig. 2 A river with no street residence

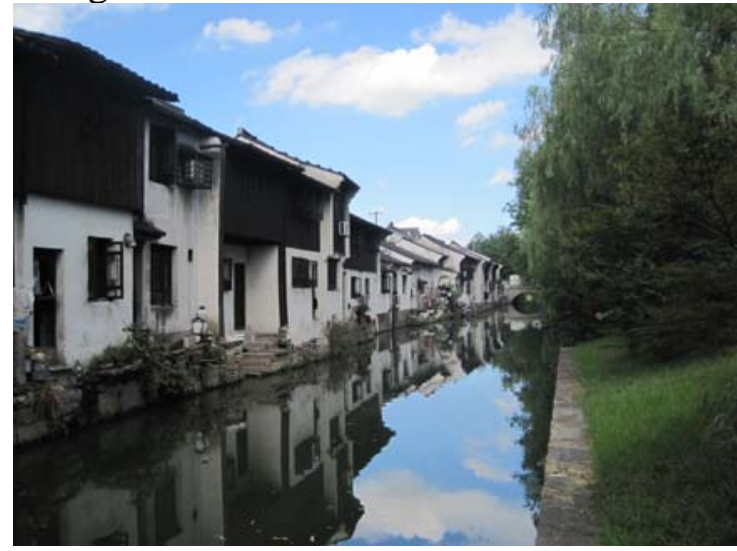

Fig. 4 A river and a street residence

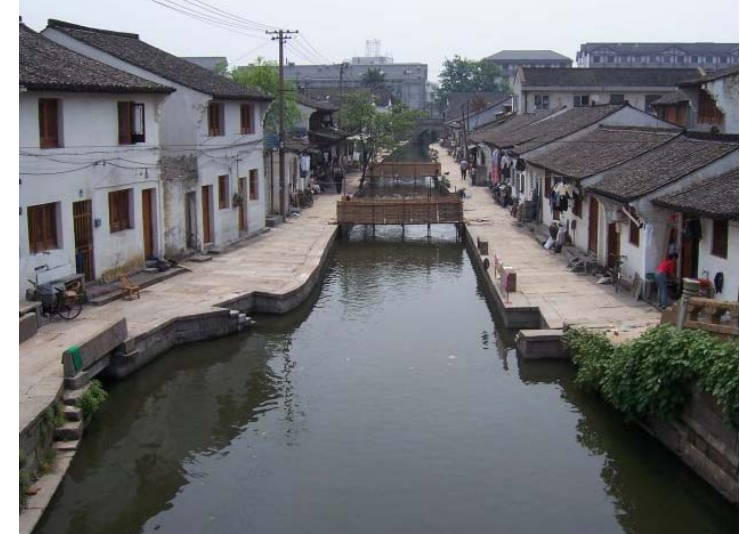

Fig. 3 Two streets mingle a river residence

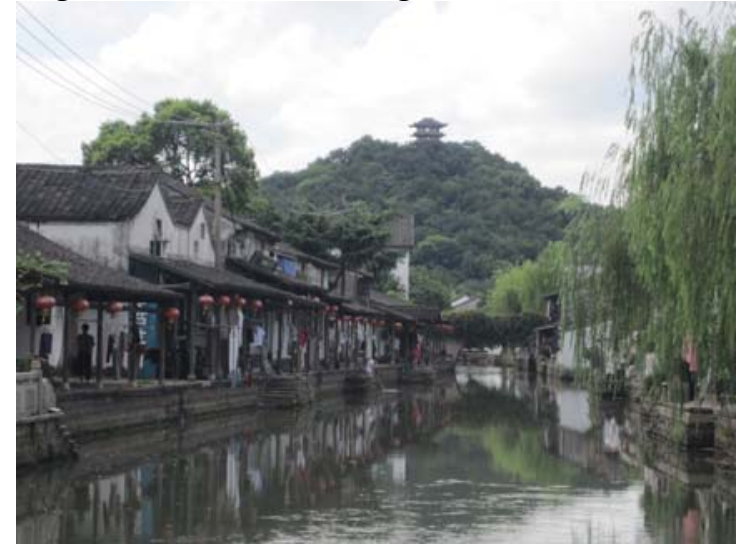

Fig. 5 A river and a covered street residence

\section{Architectural form of adjacent river residence}

The river in Shaoxing is narrow, some of them only have about 2 meters width, just like a deep water ally, and most of them are bending. Thus, the width and the flow of the river also affect the characteristics of house adjacent the water. Houses beside the coast of the water ally rarely stretch out to gain space, and they are connected by flagstone bridge making the river become a private patio. Or the house is simply built cross the river, with no regard to the river flowing under the house. When the cool breeze of the summer blows, the indoor heat will be swept away, leaving the room cozy and comfortable. Although the river is long and narrow, but the river bank is high, so building house cross the river does not affect the passing through of the ship. Perhaps, it is this particular environment that requires the light volume of the Wupeng boat, and perhaps the small Wupeng boats create the special style of the watery region.

To achieve considerable space on both side of the slightly wider river, the adjacent river houses are generally cantilevered to the river. Generally, they stretch a platform or few steps to the water surface from the external walls of the first floor, and stretch a boarded partition from the second floor, the upper and lower floors as a whole overhanging a part to the river. There are also some houses stretching the backrest rails or the corridors, and connecting to the pier. The smaller houses just stretch a stone near the bank in front of the door. These practices are simple, but maximize their living space from the surface of the water, which forms another unique architectural style of Shaoxing watery region.

\section{Private pier and public pier of adjacent river residence}


In the adjacent river residence, there is a distinctive architectural form, that is, private pier and public pier.

There are various forms of private piers in the adjacent river residence, generally built along the shore. it is shown in figure 6. And some retreat part as the concave gallery, or set up a notch to leave stopping space to adapt to the narrow river and reduce the blocking to the water transport, and is also convenient for use in rainy days. Private piers have a variety of functions, such as getting water, washing, enjoying the cool air, aboard the boat, commodity trading not ashore, and so on. At the same time, it also plays an active role in using the river wind to adjust the microclimate. Sometimes, private pier combining with the platform form a very colorful and practical living space, making private pier an important part in houses near the water. However, the public pier is the product of transport and public supporting facilities. it is shown in figure 7 . There will be a section of water dug out in a distance of the adjoining dwellings near the water to form a water plaza to build a public dock, which is convenient to ships calling and aboard, public washing, fire safety and other uses. In the prosperous areas, there are bridges to facilitate cross-bank exchanges, and near the bridge there are large public piers and taverns restaurants and so on, which often form a lively bazaar.

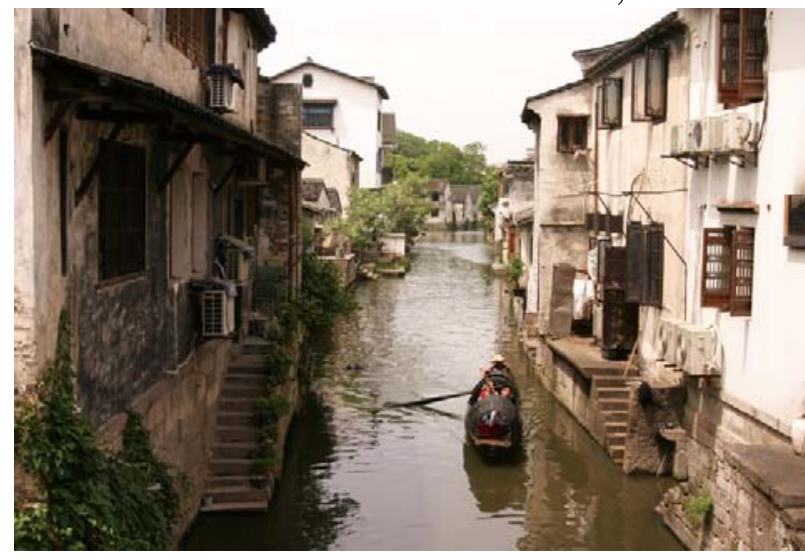

Fig.7 Private pier of adjacent river residence

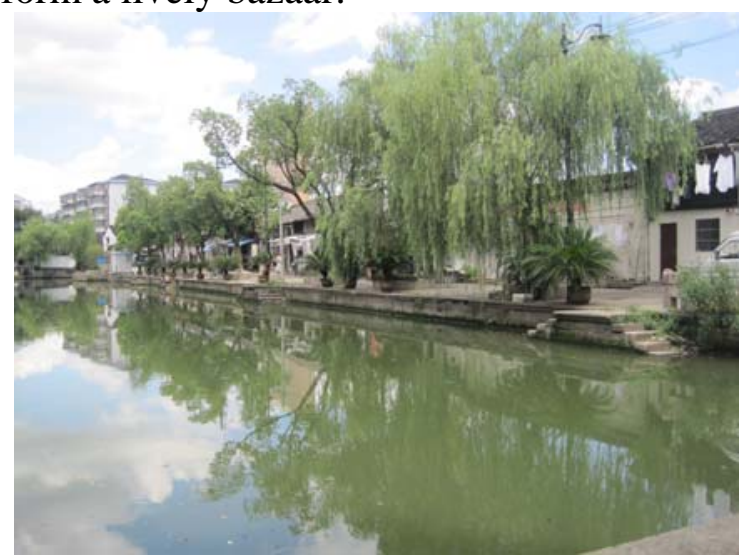

Fig.6 Public pier of adjacent river residence

\section{Summary}

The adjacent river residence is compact in layout, surrounded by street and water, with shop in front and bedroom behind. The layout is narrow and long, the design approach is clever and unique, known as "enjoy the landscape without walking out the city, enjoy the leisure life staying in the busy streets ". This exquisite ancient Yue architectural culture is particularly worthy of our protection and love, inheritance and development. However, this unique architectural environment is due to the development of history, natural conditions and people's living customs, and as the continuous development of the history, beaten track can only stifle the charm of the traditional architectural art. For the unique architectural art in Shaoxing residence, we can only seriously study, develop it in learning, innovate in development, combine the historical and cultural traditions with modern civilization and complement each other under the premise to meet the modern use.

\section{References}

[1] Z.Q.Chen: Journal of Shanghai University, Vol. 13 (2006), p. 47-52.

[2] S.Y.Zhou: Southeast Culture, Vol. 4 (1990), p. 148-153.

[3] B.X. Tang: Architectural Journal, Vol. 9 (1992), p.52-56.

[4] X.Y. Zhou, X. Ma: Chinese Architectural Culturein Jiangnan Watertown (Hubei Education Press: Wuhan 2006).

[5] S. Ji: Planners, Vol.24(2008), p. 75-78. 